\title{
A mobile application tool for standing posture analysis: development, validity, and reliability
}

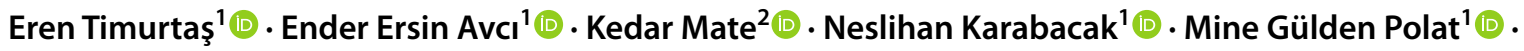 \\ ilkşan Demirbüken ${ }^{1}$ (D)
}

Received: 21 September 2021 / Accepted: 21 October 2021 / Published online: 30 October 2021

(c) The Author(s), under exclusive licence to Royal Academy of Medicine in Ireland 2021

\begin{abstract}
Background Using mobile application for postural assessments has been drawing a rising interest due to widespread use of smartphones. Although there are some mobile applications in use, validated mobile tools for accurate postural assessment are still warranted.

Aims This study aimed to develop Fizyoprint mobile application tool to assess standing posture and investigate the validity and reliability of the application in young adults.

Methods A convenience sample of 20 young adults (12 men and 8 women with a mean age of $21.3 \pm 2.2$ years) and 2 physiotherapists as raters participated in the study. The participant's digital images were obtained from the anterior, posterior, and right lateral sides. The raters selected the anatomic reference points by using digital markers in the app screen, and the Fizyoprint application, with Turkish language option, calculated a total of 26 posture variables, including 11 distance and 15 angle variables. Each participant was assessed twice (1-week interval) by 2 raters with Fizyoprint. Inter- and intra-rater reliabilities were estimated using the intraclass correlation coefficient. The BioTonix ${ }^{\mathrm{TM}}$ posture analysis system was used for validation.

Results A total of $80.7 \%$ (21 variables) indicated acceptable to excellent intra-rater reliability results. A total of $57.7 \%$ (15 variables) were found to be acceptable to excellent for inter-rater measurements. The results confirmed the validity of the Fizyoprint application for testing the standing posture.

Conclusions Fizyoprint application is a new, valid, free mobile tool with acceptable concordance with BioTonix ${ }^{\mathrm{TM}}$ postural analysis system for assessing standing posture. Further studies are warranted to test the current application in different populations and musculoskeletal conditions.
\end{abstract}

Keywords Assessment $\cdot$ Mobile applications $\cdot$ Posture $\cdot$ Reliability $\cdot$ Validity

\section{Introduction}

Ender Ersin Avc1

Kedar Mate

kedar.mate@mail.mcgill.ca

İlkşan Demirbüken

ilksan_d@hotmail.com

1 Faculty of Health Sciences, Department of Physiotherapy and Rehabilitation, Marmara University, Istanbul, Turkey

2 Centre for Outcomes Research \& Evaluation, Research Institute of the McGill University Health Centre, Montréal, Canada
Posture is the alignment of each part of the body in the most appropriate position relative to the adjacent segments and the whole body [1]. In other words, the combination of positions taken by the joints of the body with respect to gravity is defined as posture [2]. Good posture is considered to be an important health indicator [3], and optimal posture is required for balanced position of musculoskeletal system involving minimum stress and strain on the body $[2,4]$. Abnormal posture predisposes several musculoskeletal disorders including pain, impaired proprioceptive feedback, imbalance in muscle activity, abnormal load-bearing on joints and ligaments, and getting easily fatigued and even increased fall risk $[5,6]$. Assessment of the postural 
alignment is one of the most frequently performed assessments by physiotherapists and other rehabilitation professionals in all age populations due to its significant necessity to identify and manage problems rising from postural disorders [5, 7-9].

Visual inspection is a commonly used assessment method in the clinical settings, but visual inspection is lacking of scientific validation; it is highly prone to bias [10]. The literature reports a range of quantitative postural assessment techniques from the use of simple goniometerbased measurements to three-dimensional imaging technologies which are more objective measurements than visual inspection [11, 12]. However, they have some advantages and disadvantages when compared with each other. For example, while goniometer-based measurement is a userfriendly and inexpensive method, it has some methodological restrictions in the assessment of postural deviations. One of the main problems was reported as difficulty in measurements for maintaining the arm of the goniometer parallel with the horizontal axis [11]. In addition, Fortin et al. suggested that goniometer-based assessments are not only eligible for whole-body posture, but also it can be useful for just one body segment or postural variable [8]. The more advanced technologies such as $3 \mathrm{D}$ analysis systems or surface topography are accurate methods to assess posture but they tend to be very expensive and impractical for clinical settings [13, 14].

At this point, image-based technologies lent a hand to researchers and clinicians by providing accurate and accessible postural assessment tools. Various postural assessment software using digitized images where reflective markers are placed on anatomical reference points and limb segments were developed. These marker positions are captured and analyzed by the software in anterior, posterior, and lateral views and calculate body angles and distances on the images [1, 15-17].

In recent years, studies related with postural assessment tools by using mobile application (app) have been drawing rising interest due to widespread use of smartphone and its favorable technology integration in image-based apps. The review of Moreira et al. investigated the studies regarding posture assessment tools between the year 2012 and 2020, and they reported 13 mobile apps for assessing posture [12]. A majority of these apps were developed specifically for analysis of spinal orientation such as lordosis, kyphosis, scoliosis postures, and Cobb angle [18-20]. Furthermore, 11 of 13 apps were classified as sensor-based (accelerometer or gyroscope) apps that have diverse approaches such as using assessment of radiographs [21] or direct contact with the body of patients $[12,22]$. Actually, most of the imagebased solutions not only provide posture assessment for spinal orientation but also include other regions of the body by avoiding physically contact with patient and minimizing patients' exposure to radiation [12]. However, up to our knowledge, there are still limited numbers of mobile apps for posture assessment of full body segments. In addition, the current available apps in stores require to be tested for validity and reliability for their effectiveness before clinical use. The PostureScreen Mobile (PSM) app is one of the most studied apps in the literature but still needs to be further investigated, since Hopkins et al. suggested using this app with caution until next researches report additional validity and reliability data. It is essential to note that the study of Hopkins et al. is the only evidence investigating the validity of the PSM app [9].

The use of mobile technology is found to be beneficial for supporting more rapid decisions, planning, and followup of any treatment, increasing the quality of the data and data accessibility $[13,14]$. It is clear that more validated mobile apps for accurate postural assessment are still warranted. However, it is also suggested that overcoming the language barriers plays an important role in the process of implementing a user design interface that satisfies technology users [23].

In the current study, we used the image-based methodology which has been validated by several previous studies to develop a new postural assessment mobile app, Fizyoprint, including a Turkish language option. Therefore, this study aimed to investigate the validity and reliability of the Fizyoprint app tool to assess standing posture.

\section{Material and method}

\section{Study design}

The overall aim of this measurement study was to estimate the extent to which (1) two technologies provide concordant or discordant information, and (2) the Fizyoprint app provides inter- and intra-rater reliability estimates.

\section{Participants}

A convenience sample of 20 young adults, 12 men and 8 women with a mean age of 21.3 years (standard deviation: $S D=2.2$ years), were recruited between November 2017 and March 2018. Participants with current injury history or complaints of any type of pain were excluded from the study. Healthy volunteers who did not have any musculoskeletal problems (scoliosis, kyphosis, etc.), neurologic problems, congenital deformity, and severe vision impairment that would affect the postural alignment were included. The assessments were conducted at the Laboratory of Biomechanics, Faculty of Health Sciences, Marmara University. All the participants signed informed consent forms, and the project was approved by the Ethics Committee of Faculty of Health Sciences, Marmara University. 
To be included in this study, raters had to be clinical physiotherapists with minimum master's degree and with at least 3 years of clinical experience.

\section{Instrumentation}

Fizyoprint app The Fizyoprint app was developed at the Marmara University Faculty of Health Sciences. The app uses the $\mathrm{X}, \mathrm{Y}$, and $\mathrm{Z}$ coordinates as point of reference where $\mathrm{X}$ axis indicated direction from left to right, $\mathrm{Y}$ axis from forward to backward, and $\mathrm{Z}$ axis from up and down. The app allows conducting posture analysis using stored images or images captured using the smartphone camera. The participant's digital images are obtained from the anterior, posterior, and right lateral sides. The rater selects the anatomic reference points by using digital markers in the app screen, and the app calculates distances and angles. The Fizyoprint app screenshots and positions of digital markers are presented in Fig. 1.

BioTonix $^{\text {TM }}$ posture analysis system .BioTonix ${ }^{\mathrm{TM}}$ system includes a video camera, positioning platform, and software called the BioPrint ${ }^{\circledR}$. The BioTonix ${ }^{\mathrm{TM}}$ posture analysis system (Biotonix Inc., Montreal, QC, Canada) has been reported to have high reliability for posture analysis [24]. Images of a participant are obtained from three directions: anterior, posterior, and right lateral. Digital markers are positioned on anatomic reference points by using BioPrint ${ }^{\circledR}$ software [25]. The rater selects anatomic reference points on the software screen using a mouse, and the software calculates distances and angles between digital markers.
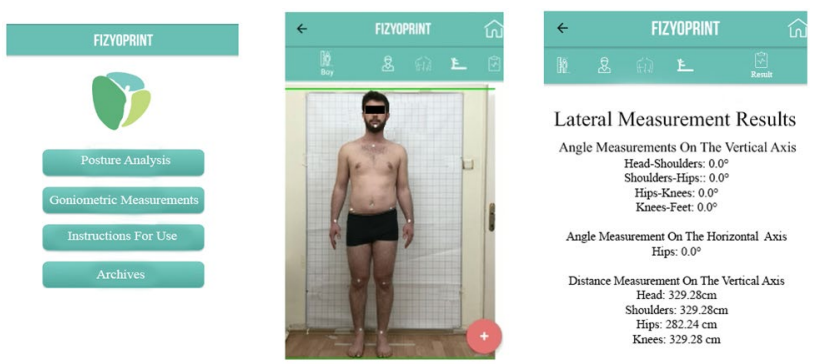

Lateral Measurement Results Angle Measurements On The Vertical Axis Head-shoulders $0.0^{\circ}$
Shoulders-Hips: $0.0^{\circ}$ Shoulders-Hips: : $0.0^{\circ}$
Hips-Knest $0.0^{\circ}$
Knees-Feet $0.0^{\circ}$

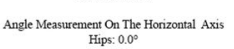
int
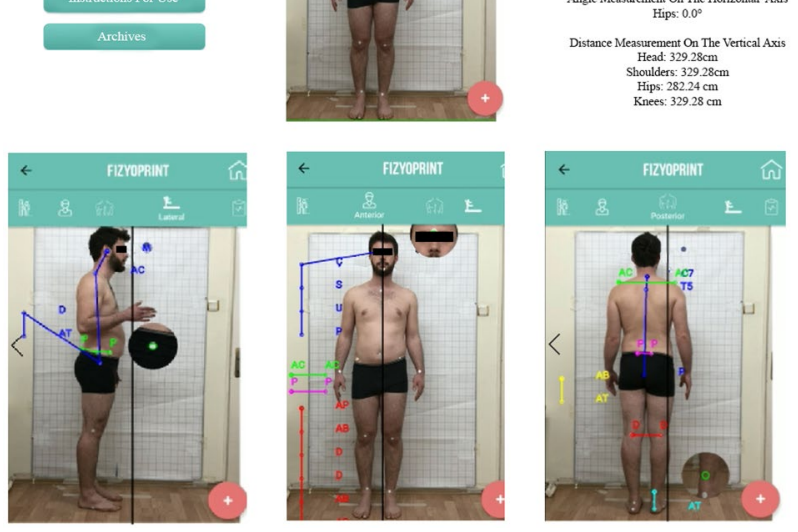

Fig. 1 Fizyoprint app screenshots and positions of digital markers

\section{Digital image acquisition}

Each participant attended an in-person image capture session. Three views of upright standing posture, anterior, posterior, and right lateral side views, were captured. Participants were made to stand approximately $30 \mathrm{~cm}$ from the center of a calibrated wall grid. The images were obtained using a digital camera (Canon EOS 250D) placed at a height of around $84 \mathrm{~cm}$ above the floor and between 2.44 and $3.35 \mathrm{~m}$ from the wall grid as shown in Fig. 1 [26]. The participants were instructed to adopt a comfortable standing position over the tape markings on the floor, weight bearing equally on both lower extremities, and focus straight ahead on a marker placed at a distance. To minimize the effect of the participant's habitual posture, each participant was asked to stand on their right and then the left foot for a few seconds and adopted a comfortable posture [15]. The participants were asked to dress such that all the 26 anatomic reference points could be seen by the camera. These points were at anterior: the mid-forehead, chin, sternum, acromion, umbilicus, iliac crest, knees, ankles; at posterior: the C7, T5, acromion, posterior iliac crest, knees, ankles; and at lateral: the mastoid process, acromion, anterior, and posterior pelvis, knee, and ankle. For posture analysis, a total of 60 images were collected by researchers, 3 from each participant.

\section{Procedure}

The analysis was carried out in two steps. In the first step, the reliability and validity were conducted for the Fizyoprint app. For reliability analysis, two raters analyzed the captured and digitized images of each participant twice by using the Fizyoprint app; the second data analysis was 1 week after the first set. To establish the validity, each rater analyzed each digitalized image using both the Fizyoprint app and BioTonix ${ }^{\mathrm{TM}}$ posture analysis system.

Both raters were trained to use the Fizyoprint app and the BioTonix ${ }^{\mathrm{TM}}$ posture analysis system including the zoom feature. All images were provided to the raters in random order (each rater received a different sequence), and no time limit to analysis was established for image analysis. The analysis results were recorded as distance and angle values.

\section{Statistical analysis}

The Shapiro-Wilk test and Levene tests were used to assess the normality and homogeneity of the variables (distances and angles between digital markers). The significance level was set at $\alpha=0.05$. All analyses were conducted using the SPSS (version 27.0.1 Armonk, NY: IBM Corp).

For reliability estimate, the intraclass correlation coefficient (ICC) was calculated for inter-rater agreement (reproducibility) and the intra-rater agreement (repeatability) [27]. 
The ICC was classified according to the methods of Wahlund, Listin, and Dworkin, and the ICC $<0.7$ were considered non-acceptable (NA), 0.71 to $<0.79$ were acceptable (A), 0.80 to $<0.89$ were very good $(\mathrm{VG})$, and 0.90 to $<1.0$ were excellent (EXC) [28].

To estimate the degree association between the app and the posture analysis, the Spearman rank correlation with 95\% confidence interval was calculated. The cutoff values for rho were as follows: $<0.2$ as poor $(\mathrm{P})$ correlation, 0.21 to $\leq 0.4$ as fair $(\mathrm{F}), 0.41$ to $\leq 0.6$ as moderate $(\mathrm{M}), 0.61$ to $\leq 0.8$ as $\operatorname{good}(\mathrm{G})$, and 0.8 to $\leq 1.0$ as VG [29]. The footnote in the tables presents the cutoff values.

\section{Results}

\section{Intra-rater reliability (repeatability)}

Table 1 shows, for the intra-rater agreement, overall, for rater 1 (R1), 27\% (7 of 26 variables) had EXC ICC, 39\% (10 of 26 variables) had VG ICC, $11 \%$ (3 of 26 variables) had A ICC, and $23 \%$ (6 of 26 variables) had NA ICC. In total, 77\% (20 of 26 variables) of measurements from R1 has ICC that was either A, VG, or EXC. Six of the 26 variables obtained from digital markers had NA ICC $(<0.07)$; specifically, these were three each for the angles and distances (pelvis anterior and horizontal angle, pelvis posterior and horizontal angle, left foot posterior and horizontal angle, umbilicus anterior and posterior distance, pelvis anterior and vertical distance, hip lateral and vertical distance).

For rater 2 (R2), 27\% (7 of 26 variables) had EXC ICC, $31 \%$ (8 of 26 variables) had VG ICC, $19 \%$ (5 of 26 variables) had a ICC, and $23 \%$ (6 of 26 variables) had NA ICC. In total, $77 \%$ (20 of 26 variables) of R2's measurements showed ICC that was either A, VA, or EXC. Six of the 26 variables measured had NA ICCs $(<0.07)$; these were four for angles and two for distances (shoulder anterior and horizontal angle, pelvis posterior and horizontal angle, both left and right foot posterior and rotation angles, T5 vertical distance, hip lateral and vertical distance).

\section{Inter-rater reliability (reproductivity)}

Table 1 shows the inter-rater agreements. Overall, $15 \%$ (4 of 26 variables) had EXC ICC, $27 \%$ (7 of 26 variables) had VG ICC, $15 \%$ (4 of 26 variables) had A ICC, and $43 \%$ (11 of 26 variables) had NA ICC. In total, $58 \%$ (15 of 26 variables) of measurements showed ICC that was either A, VG, or EXC. Eleven of 26 variables had NA ICCs $(<0.07)$. These were three for angles and eight for distances (pelvis posterior and horizontal angle, both left and right foot posterior and rotation angles, umbilicus anterior and posterior distance, pelvis anterior and vertical distance, pelvis posterior and horizontal angle, T5 vertical distance, pelvis posterior vertical distance, head lateral and vertical distance, shoulder lateral and vertical distance, hip lateral and vertical distance, knee lateral and vertical distance).

\section{Validity}

Table 2 shows the extent to which the Fizyoprint app and Biotonix ${ }^{\mathrm{TM}}$ posture analysis system provided concordant information. The correlation coefficient values for both the raters showed a high degree of concordance. Overall, R1 and $\mathrm{R} 2$ had $89 \%$ (23 of 26 variables) that were either VG, $\mathrm{G}$, or M correlations. In detail, correlations for R1 were VG correlation in $27 \%$ ( 7 of 26 variables), G correlation in $46 \%$ (12 of 26 variables), M correlation in 15\% (4 of 26 variables), and $\mathrm{F}$ correlation in $12 \%$ ( 3 of 26 variables). Those for R2 were VG correlation in 46\% (12 of 26 variables), G correlation in $31 \%$ ( 8 of 26 variables), M correlation in $11 \%$ ( 3 of 26 variables), $1 \mathrm{~F}$ correlation in $4 \%$ ( 1 of 26 variables), and $\mathrm{P}$ correlation in $8 \%$ ( 2 of 26 variables) that were found.

Among the 23 variables with correlation values of $>0.4$, the two raters differed in the strength of association on 12 variables. For instance, anterior and horizontal angles for pelvis were classified as $\mathrm{G}$ correlation $(r=0.71)$ for $\mathrm{R} 1$ and VG correlation $(r=0.85)$ for $\mathrm{R} 2$. These 12 variables are identified with an asterisk $(*)$ in Table 2.

\section{Discussion}

In this study, the validity and reliability of Fizyoprint, a newly developed mobile app for posture assessment that has a Turkish language option, were established.

A majority of the measured variables in the app have been found to have accurate intra-rater and inter-rater reliabilities. Around $80.7 \%$ (21 of 26 variables) of variables showed G to EXC intra-rater reliability $(r=>0.61)$. Acceptable levels of agreement were found between the measurements of PT raters. Over $57.7 \%$ ( 15 of 26 variables) were found to be A to EXC for inter-rater measurements $(r=X$ to $Y$ ). Moreover, the results from the present study showed that Fizyoprint had a high level of validity for assessing standing posture. Furthermore, it is accessible to local healthcare professionals as a result of the Turkish language feature.

Limited numbers of mobile apps for posture assessment have demonstrated reliability and validity. The mobile apps use different methodologies such as using markers, sensors, and photographs, and have some advantages and disadvantages when compared to each other [12]. For example, some apps are sensor based (accelerometer or gyroscope), and they were mostly developed to assess spinal orientation such as lordosis and kyphosis [30-32]. The angles and translations such as tilted positions of the body 
Table 1 Intra- and inter-rater agreements with the Fizyoprint app

\begin{tabular}{|c|c|c|c|}
\hline \multirow{3}{*}{$\begin{array}{l}\text { Measurement variables (cranial } \\
\text { to caudal) }\end{array}$} & \multicolumn{2}{|l|}{ Intra-rater } & \multirow{3}{*}{$\begin{array}{l}\text { Inter-rater } \\
\text { R1 to R2 } \\
\text { ICC classification }\end{array}$} \\
\hline & $\mathrm{R} 1$ & $\mathrm{R} 2$ & \\
\hline & ICC classification & ICC classification & \\
\hline \multicolumn{4}{|l|}{ Anterior and horizontal angles } \\
\hline Shoulder & $0.95 *$-EXC & $0.59-\mathrm{NA}$ & $0.85 *-V G$ \\
\hline Pelvis & $0.45-\mathrm{NA}$ & $0.79 *-A$ & $0.76^{*}-\mathrm{A}$ \\
\hline Knee & $0.89 *-V G$ & $0.79 *-A$ & $0.85 *-V G$ \\
\hline \multicolumn{4}{|l|}{ Anterior and vertical distances } \\
\hline Head & $0.81 *_{-V G}$ & $0.92 *$-EXC & $0.71 *-\mathrm{A}$ \\
\hline Shoulder & $0.93 *$-EXC & $0.91 *$-EXC & $0.76 *-\mathrm{A}$ \\
\hline Umbilicus & $0.66-\mathrm{NA}$ & $0.74 *-\mathrm{A}$ & $0.58-\mathrm{NA}$ \\
\hline Pelvis & $0.51-\mathrm{NA}$ & $0.76^{*}-\mathrm{A}$ & $0.57-\mathrm{NA}$ \\
\hline \multicolumn{4}{|l|}{ Anterior and rotation angles } \\
\hline Left foot & $0.95^{*}$-EXC & $0.81 *-V G$ & $0.79 *-\mathrm{A}$ \\
\hline Right foot & $0.88 *-V G$ & $0.89 *-V G$ & $0.88 *-V G$ \\
\hline \multicolumn{4}{|l|}{ Posterior and horizontal angles } \\
\hline Shoulder & $0.84 *-V G$ & $0.81 *-V G$ & $0.84 *-V G$ \\
\hline Pelvis & $0.49-\mathrm{NA}$ & 0.64-NA & $0.61-N A$ \\
\hline Knee & $0.93 *$-EXC & $0.79 *-\mathrm{A}$ & $0.91 *$-EXC \\
\hline \multicolumn{4}{|l|}{ Vertical distances } \\
\hline $\mathrm{C} 7$ & $0.87 *-V G$ & $0.89 *-V G$ & $0.86 *-\mathrm{VG}$ \\
\hline T5 & $0.76^{*}-\mathrm{A}$ & $0.69-\mathrm{NA}$ & $0.61-\mathrm{NA}$ \\
\hline Pelvis (posterior) & $0.81 *_{-V G}$ & $0.81 *-V G$ & $0.44-\mathrm{NA}$ \\
\hline \multicolumn{4}{|l|}{ Posterior and rotation angles } \\
\hline Left foot & $0.61-\mathrm{NA}$ & $0.53-\mathrm{NA}$ & $0.62-\mathrm{NA}$ \\
\hline Right foot & $0.72 *-A$ & $0.35-\mathrm{NA}$ & $0.51-\mathrm{NA}$ \\
\hline \multicolumn{4}{|l|}{ Lateral and vertical angles } \\
\hline Head to shoulder & $0.98 *$-EXC & $0.89 *-V G$ & $0.97 *$-EXC \\
\hline Shoulder to pelvis & $0.97 *$-EXC & $0.91 *$-EXC & $0.96 *$-EXC \\
\hline Hip to knee & $0.91 *$-EXC & $0.97 *$-EXC & $0.91 *$-EXC \\
\hline Knee to foot & $0.85 *-V G$ & $0.89 *-V G$ & $0.84 *-V G$ \\
\hline \multicolumn{4}{|l|}{ Lateral and horizontal angles } \\
\hline Pelvis & $0.83 *-V G$ & $0.93 *$-EXC & $0.86 *-\mathrm{VG}$ \\
\hline \multicolumn{4}{|l|}{ Lateral and vertical distances } \\
\hline Head & $0.81 *-\mathrm{VG}$ & $0.94 *$-EXC & $0.49-\mathrm{NA}$ \\
\hline Shoulder & $0.79 *-\mathrm{A}$ & $0.85 *-V G$ & $0.69-\mathrm{NA}$ \\
\hline Hip & $0.67-N A$ & $0.67-N A$ & $0.57-\mathrm{NA}$ \\
\hline Knee & $0.83 *-V G$ & $0.96 *$-EXC & $0.52-\mathrm{NA}$ \\
\hline
\end{tabular}

$N A$ non-acceptable $(I C C<0.7), A$ acceptable $(0.71<I C C<0.79), V G$ very good $(0.80<I C C<0.89), E X C$ excellent $(0.90<I C C<1.0), I C C s$ interclass correlation coefficients

*Acceptable variables segments are assessed by image-based solutions such the app in the present study. The PostureScreen Mobile (PSM) is the most cited posture assessment app based on image obtained from photos in the related literature among these apps [12]. As Fizyoprint has the similar technological platform with PSM, we discuss our results mostly with the literature investigating the reliability and validity of PSM.

\section{Intra- and inter-rater reliability}

The results showed that the measurements of the upper segments of the body were accurately assessed by both the raters. The discrepancy, in other words, lower ICCs, was seen when the raters assessed the lower part of the body. The variables classified as NA or A by the two raters were 
Table 2 Spearman's rank correlation between Fizyoprint app and BioTonix ${ }^{\mathrm{TM}}$ posture analysis system

\begin{tabular}{|c|c|c|}
\hline $\begin{array}{l}\text { Measurement levels } \\
\text { (cranial to caudal) }\end{array}$ & $\begin{array}{l}\text { Fizyoprint-BioTonix }^{\mathrm{TM}} \\
\text { (R1) } \\
\text { r-Classification }\end{array}$ & $\begin{array}{l}\text { Fizyoprint-BioTonix }{ }^{\mathrm{TM}} \\
\text { (R2) } \\
\text { r-Classification }\end{array}$ \\
\hline \multicolumn{3}{|c|}{ Anterior and horizontal angles } \\
\hline Shoulder & $0.75 *-G$ & $0.61 *-G$ \\
\hline Pelvis & $0.71 *-G$ & $0.85 *-V G$ \\
\hline Knee & $0.96 *-V G$ & $0.82 *-V G$ \\
\hline \multicolumn{3}{|c|}{ Anterior and vertical distances } \\
\hline Head & $0.77 *-G$ & $0.81 *-V G$ \\
\hline Shoulder & $0.93 *$ VG & $0.77 *-G$ \\
\hline Umbilicus & $0.76 *-G$ & $0.51 *-M$ \\
\hline Pelvis & $0.74 *-G$ & $0.54 *-M$ \\
\hline \multicolumn{3}{|c|}{ Anterior and rotation angles } \\
\hline Left foot & $0.33-\mathrm{F}$ & $0.09-\mathrm{P}$ \\
\hline Right foot & $0.53 *-M$ & $0.62 *-G$ \\
\hline \multicolumn{3}{|c|}{ Posterior and horizontal angles } \\
\hline Shoulder & $0.80 *-G$ & $0.93 *-V G$ \\
\hline Pelvis & $0.74 *-G$ & $0.72 *-G$ \\
\hline Knee & $0.96 *-V G$ & $0.95 *-V G$ \\
\hline \multicolumn{3}{|l|}{ Vertical distances } \\
\hline $\mathrm{C} 7$ & $0.80 *-G$ & $0.94 *-V G$ \\
\hline T5 & $0.71 *_{-G}$ & $0.74 *-G$ \\
\hline Pelvis (posterior) & $0.48 *-M$ & $0.66 *_{-G}$ \\
\hline \multicolumn{3}{|c|}{ Posterior and rotation angles } \\
\hline Left foot & $0.71 *_{-G}$ & $0.68 *_{-G}$ \\
\hline Right foot & $0.52 *-M$ & $0.52 *-M$ \\
\hline \multicolumn{3}{|c|}{ Lateral and vertical angles } \\
\hline Head to shoulder & $0.96 *-V G$ & $0.94 *-V G$ \\
\hline Shoulder to pelvis & $0.83 *-V G$ & $0.81 *-V G$ \\
\hline Hip to knee & $0.35-\mathrm{F}$ & $0.39-\mathrm{F}$ \\
\hline Knee to foot & $0.87 *$ VG & $0.83 *-V G$ \\
\hline \multicolumn{3}{|c|}{ Lateral and horizontal angles } \\
\hline Pelvis & $0.80 *-V G$ & $0.90 *-V G$ \\
\hline \multicolumn{3}{|c|}{ Lateral and vertical distances } \\
\hline Head & $0.61 *-G$ & $0.81 *-V G$ \\
\hline Shoulder & $0.66 *-G$ & $0.82 *-V G$ \\
\hline Hip & $0.32-\mathrm{F}$ & $0.18-\mathrm{P}$ \\
\hline Knee & $0.55 *-M$ & $0.71 *-G$ \\
\hline
\end{tabular}

$P$ poor $(r \leq 0.2), F$ fair $(0.21$ to $\leq 0.4), M$ moderate $(0.41$ to $\leq 0.6), G$ good $(0.61$ to $\leq 0.8), V G$ very good $(0.8$ to $\leq 1.0)$

*Acceptable variables

related with pelvis angles viewed from the anterior and posterior horizontally. Similar results were found for both the left and right foot angles at posterior and rotation. The anterior and vertical umbilicus and pelvis distance variables were found to be NA and A by R1 and R2, respectively. For R1 and R2 intra-rater measurements, $69.2 \%$ (18 variables) and $61.5 \%$ (16 variables) showed VG to EXC reliability, respectively. Approximately $19.2 \%$ of the variables ( 8 variables) were within the acceptable ranges (0.72 to 0.79$)$.
Scusz et al. used PSM to reveal postural changes in angulations and translations of head and shoulder during use of different technological devices (iPad, mobile, laptop). The authors reported that handheld mobile devices would alter the posture of the upper part of the body to a greater extent than a laptop computer [33]. A previous study by the same research group included twenty healthy individuals and two trained raters in their study design. Twenty of the 39 variables in sagittal and coronal planes from the upper and lower parts of the body were selected to test three different 
standing positions [14]. As a result, they reported that intraand inter-rater reliabilities of PSM were found to be G to EXC for all translations and that the ICCs of the translation variables were stronger than those for the angulations. This paper showed 11 translation and 15 angulation variables in the Fizyoprint app. In comparison to findings from Scusz et al., the present study showed similar intra-rater reliability for both angulation and distance variables, whereas the interrater reliability was different from each other. The majority of the ICC values of angulation variables had G to EXC reliability. Only vertical distances of C7 had EXC inter-rater reliability and anterior vertical head and shoulder distances were in the acceptable ranges (Table 1).

A similar study investigated the reliability of postural shift variables such as head, shoulder, hip, and knee tilts by three raters in a sample of 10 healthy individuals using the PSM app. The authors assessed 11 variables and compared the reliability between the two conditions: participants minimally dressed or fully dressed. The intra- and inter-rater reliabilities ranged from 0.26 to 0.93 . The study recommended using PSM procedure in minimally dressed conditions and prior training of the raters to improve rater reliability [15]. In accordance with the recommendation, the current study assessed all the participants in minimally dressed condition and trained the raters. Our raters were physical therapists who were familiar with using Web-based BioTonix PosturePrint software to assess standing posture but had no experience with Fizyoprint. To account for that, prior to the testing with the Fizyoprint, the raters were explained the process by the developer of the app. Therefore, the results from this study suggest that the Fizyoprint is a reliable tool, as the majority of the measurements showed high rates of ICCs.

\section{Validation of the Fizyoprint}

The validity of the Fizyoprint was established with the BioTonix ${ }^{\mathrm{TM}}$ PosturePrint software, which is shown to be a reliable and valid tool to assess whole-body posture and is well cited in the literature [26, 34, 35]. Our results showed M to VG correlation between measurements between the Fizyoprint and BioTonix for a majority (Table 2 ) of the variables. The correlations were $\mathrm{P}$ to $\mathrm{F}$ for hip to knee and left foot (anterior and rotation) angulations and hip (lateral and vertical) distances by both R1 and R2 (Table 2). A study by Hopkins and colleagues evaluated the validity and reliability using the PSM and 3D motion analysis system (a gold standard) to assess shift and tilt of the head, shoulders, hips, and knees from the frontal and sagittal planes (a total of 10 variables). The results showed that only the head shift in the frontal and sagittal planes was comparable with 3D systems [9]. However, these motion capture systems are quite expensive and require extensive data processing and are not easily accessible outside the research laboratory. In the current study, the
BioTonix posture analysis system was chosen for validation as it is a widely available and relatively inexpensive validated postural assessment tool [15]. Furthermore, other studies carrying similar posture assessment methods based on photographic measurements indicated that these photographic tools were reliable for the assessments of posture by high ICC results of intra- and inter-raters' evaluations [36, 37].

Most of the previous studies related with postural assessments based on photographic measurements focused on spinal alignment including head posture, especially in schoolaged children or young adult population $[8,9,13,14,35$, 37, 38]. Furthermore, a majority of them were performed with mobile postural assessment tools focused on the reliability and validity of the app among healthy individuals. Similarly, the participants in the current study were recruited from young and healthy adult population. The reliability and validity of the Fizyoprint in different age groups and different musculoskeletal problem associated with postural alterations are yet to be documented. Further studies should focus on investigating the accuracy of the app to detect postural changes in various conditions.

We anticipate a wider acceptance for the Fizyoprint app among healthcare professionals, as it is a time-effective method compared with BioTonix which requires marker placement and analysis using additional software. Studies have reported that posture assessment using a mobile app tool was found to be user-friendly and faster in providing usable information than other standard techniques [9, 14]. The Fizyoprint is an excellent option in the current pandemic COVID-19 situation, as it does not require any proximity to the participant as needed when using markers, thereby reducing the risk of physical contact.

Furthermore, we expect that the Turkish language option in Fizyoprint will have a wider uptake among the Turkish healthcare professionals and eliminate the barriers associated with using technologies in non-native languages.

In summary, the Fizyoprint will offer a great opportunity to assess posture quantitatively in a clinical setting and in research.

\section{Conclusion}

This study highlights that the Fizyoprint app has quite acceptable inter- and intra-rater reliabilities and is a valid tool for identifying static standing posture. It is worthy to note that most of the current mobile apps have limited to no data on reliability and validity. The Fizyoprint app should be considered a new and free mobile tool for measuring standing posture besides other widely used apps.

Author contribution ET has contributed to the conceptualization, designing, writing, founding, data collection, and data analyzing. EEA 
has contributed to the designing, writing, data collection, data analyzing, and literature reviewing. NK has contributed to the designing, writing, data collection, data analyzing, and literature reviewing. KM has contributed to the conceptualization, designing, writing, founding, data collection, and data analyzing. MGP has contributed to the conceptualization, writing, founding, data analyzing, and critical review. ID has contributed to the conceptualization, supervision, writing, founding, data analyzing, and critical review.

Funding This work was supported by the Marmara University, Scientific Research Projects Unit with project no. SAG-C-YLP-130116-0005.

Data availability Not applicable.

Code availability Not applicable.

\section{Declarations}

Ethics approval All the procedures performed in the studies involving human participants were in accordance with the ethical standards of the Ethics Committee of Faculty of Health Sciences, Marmara University (Approval Number: 09.2021.1012) and with the 1964 Helsinki declaration and its later amendments or comparable ethical standards.

Consent to participate Informed consent was obtained from all individual participants included in the study.

Consent for publication Not applicable.

Conflict of interest The authors declare no competing interests.

\section{References}

1. Ferreira EA, Duarte M, Maldonado EP et al (2010) Postural assessment software (PAS/SAPO): validation and reliability. Clinics (Sao Paulo) 65(7):675-681. https://doi.org/10.1590/S180759322010000700005

2. Castro A, Pacheco J, Lourenço C et al (2017) Evaluation of spinal posture using Microsoft Kinect: a preliminary case-study with 98 volunteers. Porto biomedical J 2(1):18-22

3. McEvoy MP, Grimmer K (2005) Reliability of upright posture measurements in primary school children. BMC Musculoskelet Disord 6(1):35. https://doi.org/10.1186/1471-2474-6-35

4. Haughie LJ, Fiebert IM, Roach KE (1995) Relationship of forward head posture and cervical backward bending to neck pain. J Manual \& Manipulative Therapy 3(3):91-97

5. Balzini L, Vannucchi L, Benvenuti F et al (2003) Clinical characteristics of flexed posture in elderly women. J Am Geriatr Soc 51(10):14191426. https://doi.org/10.1046/j.1532-5415.2003.51460.x

6. Swann J (2009) Good positioning: the importance of posture. Nursing And Residential Care 11(9):467-469

7. Demirbüken İ, Özgül B, Timurtaş E et al (2016) Demographic characteristics related to body posture in early adolescence. $\mathrm{J}$ of Exercise Therapy and Rehabilitation 3(3):84-89

8. Fortin C, Feldman DE, Cheriet F, Labelle H (2011) Clinical methods for quantifying body segment posture: a literature review. Disabil Rehabil 33(5):367-383. https://doi.org/10.3109/09638288.2010. 492066

9. Hopkins BB, Vehrs PR, Fellingham GW et al (2019) Validity and reliability of standing posture measurements using a mobile application. $\mathbf{J}$ of manipulative and physiological therapeutics 42(2):132-140
10. Tyson SF, DeSouza LH (2003) A clinical model for the assessment of posture and balance in people with stroke. Disabil Rehabil 25(3):120-126. https://doi.org/10.1080/0963828021000013944

11. Kandasamy G, Bettany-Saltikov J, Van Schaik P (2020) Posture and back shape measurement tools: a narrative literature review. Spinal Deformities in Adolescents, Adults and Older Adults

12. Moreira R, Teles A, Fialho R et al (2020) Mobile applications for assessing human posture: a systematic literature review. Electronics 9(8):1196

13. Fortin C, van Schaik P, Aubin-Fournier JF et al (2018) The acceptance of the clinical photographic posture assessment tool (CPPAT). BMC Musculoskelet Disord 19(1):366. https://doi.org/ 10.1186/s12891-018-2272-7

14. Szucs KA, Brown EVD (2018) Rater reliability and construct validity of a mobile application for posture analysis. J Phys Ther Sci 30(1):31-36. https://doi.org/10.1589/jpts.30.31

15. Boland DM, Neufeld EV, Ruddell J et al (2016) Inter-and intrarater agreement of static posture analysis using a mobile application. J of physical therapy science 28(12):3398-3402

16. Jones A, Sealey R, Crowe M, Gordon S (2014) Concurrent validity and reliability of the simple goniometer iPhone app compared with the universal goniometer. Physiother Theory Pract 30(7):512-516. https://doi.org/10.3109/09593985.2014.900835

17. Reina N, Cognault J, Ollivier M et al (2018) The CJOrtho app: a mobile clinical and educational tool for orthopedics. Orthop Traumatol Surg Res 104(4):523-527. https://doi.org/10.1016/j. otsr.2018.01.022

18. Kunkle WA, Madden M, Potts S (2017) Validity of a smartphone protractor to measure sagittal parameters in adult spinal deformity. Spine J 17(10):1559-1564. https://doi.org/10.1016/j.spinee.2017.06.014

19. Mazzuia ARO, Machado DR, Fukumothi DK et al (2015) Iphone app use to Cobb angle in adolescent idiopathic scoliosis: does this apply? Coluna/Columna 14:101-104

20. Waś J, Sitarski D, Ewertowska P et al (2020) Using smartphones in the evaluation of spinal curvatures in a sagittal plane. Advances in Rehabilitation 30(4):29-38

21. Allam Y, El-Fiky T, Farghally MY et al (2016) Comparison between Oxford Cobbmeter and digital Cobbmeter for measurement of Cobb angle in adolescent idiopathic scoliosis. European Spine J 25(2):444-449

22. Qiao J, Xu L, Zhu Z et al (2014) Inter- and intraobserver reliability assessment of the axial trunk rotation: manual versus smartphoneaided measurement tools. BMC Musculoskelet Disord 15(1):343. https://doi.org/10.1186/1471-2474-15-343

23. Ross J, Gao J (2016) Overcoming the language barrier in mobile user interface design: a case study on a mobile health app. arXiv preprint

24. Normand MC, Harrison DE, Cailliet R et al (2002) Reliability and measurement error of the BioTonix video posture evaluation system-part I: inanimate objects. J Manipulative Physiol Ther 25(4):246-250. https://doi.org/10.1067/mmt.2001.123169

25. Ribeiro AFM, Bergmann A, Lemos T et al (2017) Reference values for human posture measurements based on computerized photogrammetry: a systematic review. $\mathrm{J}$ of manipulative and physiological therapeutics 40(3):156-168

26. Lafond D, Descarreaux M, Normand MC, Harrison DE (2007) Postural development in school children: a cross-sectional study. Chiropr Osteopat 15(1):1. https://doi.org/10.1186/1746-1340-15-1

27. Weir JP (2005) Quantifying test-retest reliability using the intraclass correlation coefficient and the SEM. The J of Strength \& Conditioning Research 19(1):231-240

28. Wahlund K, List T, Dworkin SF (1998) Temporomandibular disorders in children and adolescents: reliability of a questionnaire, clinical examination, and diagnosis. J Orofac Pain 12(1):42-51

29. Prematunga RK (2012) Correlational analysis. Aust Crit Care 25(3):195-199. https://doi.org/10.1016/j.aucc.2012.02.003 
30. Bucke J, Spencer S, Fawcett L et al (2017) Validity of the digital inclinometer and iPhone when measuring thoracic spine rotation. $\mathrm{J}$ of athletic training 52(9):820-825

31. Chen C, Yu R, Xu W et al (2020) A practical study of diagnostic accuracy: scoliosis screenings of middle school students by a trained nurse with a smartphone versus a spine surgeon with a scoliometer. Spine (Phila Pa 1976) 45 (5):E266-E271. https://doi. org/10.1097/BRS.0000000000003256

32. Lee JB, Kim IS, Lee JJ et al (2019) Validity of a smartphone application (Sagittalmeter Pro) for the measurement of sagittal balance parameters. World Neurosurg 126:e8-e15. https://doi.org/ 10.1016/j.wneu.2018.11.242

33. Szucs KA, Cicuto K, Rakow M (2018) A comparison of upper body and limb postures across technology and handheld device use in college students. $\mathrm{J}$ of physical therapy science 30(10):1293-1300

34. Janik TJ, Harrison DE, Cailliet R et al (2007) Validity of a computer postural analysis to estimate 3-dimensional rotations and translations of the head from three 2-dimensional digital images. J Manipulative Physiol Ther 30(2):124-129. https://doi.org/10. 1016/j.jmpt.2006.12.005
35. Özyürek S, Genç A, Karaali HK, Algun ZC (2017) Threedimensional evaluation of pelvic posture in adolescents with and without a history of low back pain. Turkish $\mathrm{J}$ of medical sciences 47(6):1885-1893

36. Pausic J, Pedisic Z, Dizdar D (2010) Reliability of a photographic method for assessing standing posture of elementary school students. J Manipulative Physiol Ther 33(6):425-431. https://doi.org/ 10.1016/j.jmpt.2010.06.002

37. Ruivo R, Pezarat-Correia P, Carita A, Vaz J (2013) Reliability and validity of angular measures through the software for postural assessment. Postural Assessment Software Rehabilitación 47(4):223-228

38. Hazar Z, Karabicak GO, Tiftikci U (2015) Reliability of photographic posture analysis of adolescents. J Phys Ther Sci 27(10):3123-3126. https://doi.org/10.1589/jpts.27.3123

Publisher's Note Springer Nature remains neutral with regard to jurisdictional claims in published maps and institutional affiliations. 